\title{
FEMMES DE RACINE
}

\section{Antigone}

Fille maudite de l'amour incestueux, Ton sang pur est trahi par la rage céleste, Si tu t'abandonnes au délice amoureux, Tu reconnaîtras ces vils dieux qui te détestent.

Tu aimas tes frères, tu pleuras leur malheur, Et tes larmes, comme des perles d'espérance, Coulaient doucement sur la fatale rigueur Qui t'accable de sa cruelle indifférence.

Ne rêve plus auprès de l'aimable Hémon, Toi, désir enflammé du cupide Créon, Amante condamnée des amours interdites.

Antigone, tes lèvres ont le goût amer Du filtre empoisonné que tendit Aphrodite, Promesse de l'amour et chemin de l'enfer.

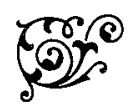




\section{Andromaque}

Eve ensorceleuse des vestiges de Troie,

Du haut de ses murs tu regardas le carnage

Où d'Achille vainqueur Hector devint la proie,

Te confiant son fils comme objet de chantage.

Captive couronnée, reine de séduction, Offerte aux tristes joies du coupable adultère, Renieras-tu les souvenirs de l'Ilion

Où s'agitent ta foi et ton devoir de mère?

Dans tes bras affolés tu serres ton enfant, Le couvres de baisers, l'appelles ton amant, Et le feu de ta folie te rend désirable.

Tu préfères la mort à l'infidélité, Car sacrifier ton corps est trop insupportable, Ta chair l'emporte donc sur ta maternité.

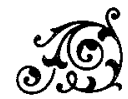




\section{Junie}

Nudité désirée, triste fille de l'ombre, Toi, filtre capiteux d'un tyran couronné, Ta vertu est le vin qui grise l'heure sombre D'une nuit enflammée par ta virginité.

Rivale maudite des amours maternelles, Douce consolation d'un prince malheureux, Si ta chair convoitée en ce jour se rebelle, Ton amant périt sous ton regard vertueux.

Tandis que tu gémis, vestale confondue, Que le Bien et le Mal en ce jour s'entretuent, Tes ennemis se livrent une guerre intestine.

Ton amant empoisonné n'est pas un butin, C'est la gloire du fils ou l'orgueil d'Agrippine, Qui scelle à tout jamais ton sacré destin.

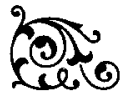




\section{Bérénice}

Princesse vieillie sous les caresses trompeuses, Amoureuse grisée qui croyait triompher, Le deuil de Titus ouvre la nuit ténébreuse

Où tes folâtres amours de mort sont frappées.

Ton exotique beauté était sans rivale, Vespasien comblait d'ardeur sa Rome éblouie, Deux maîtresses régnaient en superbes égales, A toi le fils, au père la Ville alanguie.

Mais que peux-tu contre la tenace chaleur Dont brûle le désir d'un nouvel empereur? Rome abandonnée s'offre à l'éclat juvénile.

O Bérénice, connais la mâle ambition, L'amour était une rêverie volatile Que le goût du pouvoir transforme en trahison.

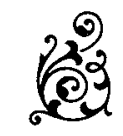




\section{Roxane}

Odalisque de sérail, au destin si frêle, Concubine d'un roi que la beauté séduit, Tu n'as pas cru, hélas, qu'un amour infidèle Te livrerait à une Parque sans merci.

Trop éblouie par ton éphémère couronne, Tu voulus posséder l'aimable Bajazet, Mais le péché maudit où tes sens s'abandonnent De la trahison te fit le risible objet.

Roxane de l'Orient, fille de l'illusion, Favorite des grands, mais proie de l'ambition, Ne connais-tu pas le sort d'une courtisane?

Tes appas enchantent les plaisirs des caresses, Mais aux délices de ton beau corps de sultane, L'ingrat préfère le charme d'une princesse.

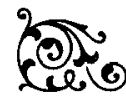




\section{Monime}

Maîtresse d'un royaume, esclave de l'envie,

Tendre convoitise de princes ambitieux,

Reine de Nymphée à ta foi assujettie,

Prisonnière de l'amour, comme de tes voeux.

Le roi te possède, ses deux fils te désirent,

Tu crains la honte de ton infidélité,

Mais dans ton coeur que tes sens enfiévrés déchirent,

Xipharès triomphe de ta fragilité.

Du mensonge souverain tu seras la proie,

Et ta bouche aimante trahira ton émoi.

Pourquoi écoutais-tu un vieillard imbécile?

Monime, si constante et pure en tes amours, Toi, destinée au sort d'une fille docile, Un linceul te sera d'un éternel secours.

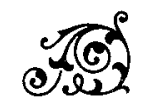




\section{Iphigénie}

Douce fille d'un roi poltron et pitoyable, Aimée d'Achille, cet impétueux soldat. La haine et la peur d'une foule misérable A des dieux insensés vont offrir ton trépas.

Tes larmes et ta tendresse supplient ton père, Ton innocence craint la froideur de l'épée, Inutiles pleurs contre un jugement sévère Qu'un prêtre haineux contre toi a prononcé.

Vois-tu comment les hommes insultent le ciel Quand ils s'égarent en d'absurdes rituels, Quand leur amour meurt sous des prières hostiles?

L'erreur te sauvera de la persécution, Mais dans la mort de la sinistre Eriphile Tu reverras la source des superstitions.

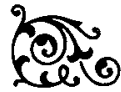




\section{Phèdre}

De Pasiphaé tu hérites la luxure,

Insatiable femme dont les flancs en feu

Infestent Trézène de leur passion impure,

Et le fils de Thésée d'un criminel aveu.

Aux Dieux cruels tu te proclames innocente, Victime de Vénus et de son mauvais sort.

Mais au fond de ton âme où ton désir serpente,

Tu connais ton péché et son masque de mort.

Tes lèvres brûlent de dire la vérité,

Mais tes sens embrasent ta culpabilité,

Et au mal d'aimer succède la jalousie.

O Phèdre, possédée d'amour et d'abandon, Ton amant sera la proie de la perfidie

Que ton sauvage coeur a vouée au démon.

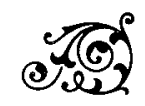




\section{Esther}

Toi, chaste favorite d'un roi adultère, Eprise de ta race, de Dieu reconnue,

T'es-tu abandonnée au délice éphémère

De l'hymen, ou à la gloire du peuple élu?

Fille de Mardochée, femme d'Assuérus, En ta douce piété, trop aimable princesse, Tu es l'épouse de l'originel Cyrus, $\mathrm{Au}$ mépris de ta chair et des tendres caresses.

Ta ruse innocente confond ton ennemi, Tes charmes triomphent d'un crédule mari, Suppliques ou larmes, tu es irrésistible.

Sublime prêtresse d'une nation sauvée, Aux prières d'Aman tu restes insensible, Car ta cruelle foi ignore la pitié.

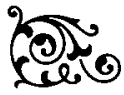




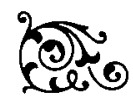

\section{Athalie}

Marâtre sans remords qu'un enfant ensorcelle,

Rivale détestée des disciples de Dieu, Es-tu sensible à la tendresse maternelle, Ou songerais-tu à Jérusalem en feu?

Un rêve vint troubler ta mémoire fébrile, A Jézabel tu tendis tes coupables bras, Mais dans l'horreur de cette longue nuit hostile Le divin vengeur t'a condamnée au trépas.

Cupide Athalie, dupée par l'émotion, Ton âme est envahie par un Dieu sans pardon. La grâce d'Eliacin t'entraîne à ta perte.

Trompée par la ruse du grand-prêtre ennemi, Tu te précipites dans la tombe entrouverte Où du Dieu cruel tu découvres le défi.

Constant Venesoen (University of Western Ontario) 